\title{
Health Workers' Competence in Diagnosis and Management of Post Traumatic Stress Disorder among Internally Displaced Persons in Plateau State, Nigeria
}

\author{
Ajio Daniel K. \\ Department of Nursing science, \\ University of Jos, Nigeria \\ Salihu Dauda \\ Department of Nursing Services, Yobe State \\ Hospitals Management Board Damaturu
}

\author{
Ogunyewo, A.O. \\ Department of Nursing science, \\ University of Jos, Nigeria \\ Gusen Nanle Joseph \\ Department of Nursing science, \\ University of Jos, Nigeria
}

\begin{abstract}
Objectives: is to determine the health workers' perceived competence in the diagnosis and management of PTSD

Methods: focus group discussion was employed with health workers working with the internally displaced persons in Plateau state Nigeria.

Results: health workers in Plateau state lacked full competence in the diagnosis and management of post traumatic stress disorder. Furthermore, they are partially competence in the basic life support skills as well as the referral of cases of PTSD.
\end{abstract}

Conclusion: health workers need more knowledge and training on the management of post traumatic stress disorders.

KEYWORD: Health Workers, Competence, Diagnosis, Trauma, Stress and Disorder

\section{INTRODUCTION}

Emergencies and disasters, both man-made and natural, are on the increase in our contemporary society, threatening and traumatizing people globally, including Nigeria. When disasters strike with associated challenges, health workers like nurses, medical officers and community health extension workers are usually called upon for assistance and care of the victims of these catastrophic events/incidents.
Loke and Fung (2013) submitted that health workers like nurses require the necessary knowledge and abilities to meet the needs of disaster sufferers in their respective serving communities. The importance of determining health workers' knowledge and abilities in the diagnosis and management of Post Traumatic Stress Disorder (PTSD) following traumatic experiences need not therefore, be over emphasized.

Post traumatic stress disorder (PTSD) is a mental health problem that some people develop after experiencing or witnessing a life-threatening event like, combat, a natural disaster, a car accident, or sexual assault (National Centre For PTSD, 2016). In the past, it was known by several other names like "the soldier's heart", "shell shock" (Minds, 2014). Post Traumatic Stress Disorder may be acute, chronic or of delayed onset. It can be diagnosed via criteria like its clusters of symptoms (which includes reliving, avoidance and hyper arousal), DSM-IV (R) and ICD10 ; and may majorly be managed psychotherapeutically and by pharmacotherapy as well (APA, 2013).

Today, the term PTSD can be used to describe the psychological problems resulting from any traumatic event that overwhelms and makes one feel helpless (Garette, 2001; Duckworth, 2013; Smith \& Segal, 2015).

Competence in Diagnosis and Management of PTSD Now that disasters are occurring more frequently around the world with associated challenges like PTSD, the need to prepare health workers for disaster is obvious (Usher et al, 2010; Loke \& Fung, 2014). It 
was recommended by the World Health Organization that all nations, no matter how frequent (or infrequent) the happenings, should prepare healthcare workers for a disaster and consequences (Weiner, 2005). Health workers like medical officers, community health officers and nurses' clinical competence is vital to ensure safe and high quality care, and the continued assessment of such clinical competence is of major concern. (Finnbakk, 2015). College of Registered Nurses of British Columbia (CRNBC, 2015) considered competence as the habitual and judicious use of communication, knowledge, technical skills, clinical reasoning, emotion, values and reflection in daily practice for the benefit of the individual and community being served. This college maintained further that, professional competence is developmental, impermanent and context-dependent; and that, there is no best known way to measure competence. Competence can however be broken into a series of measurable competencies. Competence here relies on competencies, which can be thought of as Facets of Competence. (Cane, 2013).

Competencies are statements about the knowledge, skills, attitudes and judgments to perform safely and ethically with in an individual's practice or in a designated role or setting (CRNBC, 2015).

Competencies are therefore, abilities to perform a job or task with a specified level of proficiency. They are underpinned by their related knowledge, skills and abilities. The identified competencies incorporate those of advanced practice and specifically address the activities that are included in the additional legislated scope of practitioners, such as health assessment, diagnosis of acute and chronic illnesses and their therapeutic management, PTSD inclusive (Johnson \& Johnson, 2016).

Why should we be concerned about Health workers' competence in diagnosis and management of PTSD? It is because health workers encounter IDPs who are victims of violence (Trauma) and attend to their physical and psychological needs more than others that are also in the helping relationship with them. Their roles in diagnosis and treatment of PTSD is therefore, very crucial. Specifically, and to the best of my knowledge, no work has been done on the perceived competence of health workers who worked with the IDPs, in the recognition and management of PTSD in Plateau state of Nigeria, hence the need for this work.

\section{THE AIM OF THE STUDY}

The main aim of this study therefore, is to determine the health workers' perceived competence in the diagnosis and management of PTSD in Plateau state of Nigeria, and further, to discuss the implications for PTSD- focussed training.

\section{METHODOLOGY}

Focus Group Discussions were employed in this study among the health personnel that worked with the internally displaced persons (IDPs) in Camps for the last six months in Plateau state government of Nigeria. Health workers were grouped into three i.e 1) The nursing officers 2) Community/public Health officers, and 3) The medical officers. Two Discussions were held with each group separately and the last meeting was the summary/consensus reached by each group regarding their competences about PTSD diagnosis and management. The health personnel working with the IDPs in the camp at BUKURU were identified through the Camp Director of the STEFHANOS Foundation, that also granted the formal permission for the study to be conducted at the site, following formal ethical clearance from the Plateau State Specialist Hospital, Jos, Nigeria. FGD guides used were based on ICN framework and World Health Organization WHO (2014) standards for disaster management/ psychological care, APA ( 2013- DSM-5) and clusters of PTSD symptoms in PTSD-8 short form (Maj Hansen, et al 2016).

Specific questions were asked on the health workers' abilities to recognize clusters of PTSD symptoms and care modalities.

\section{ANALYSIS}

\section{THE PARTICIPANTS}

Twenty (20) health workers participated in this study; 14 of them were females, while 6 were males. These health workers were stratified into three (3) focus groups (F Gs). 
Table 1: Number of participants (HWS) in the Focus Groups Discussions

\begin{tabular}{|c|c|c|c|}
\hline No of participants & $\begin{array}{c}\text { Nursing officers (NOS) } \\
(\mathrm{n}=6)\end{array}$ & $\begin{array}{c}\text { Community/Public } \\
\text { Health officers } \\
(\mathrm{C} / \text { PHOs })(\mathrm{n}=12)\end{array}$ & $\begin{array}{c}\text { Medical officers MOs } \\
(\mathrm{n}=2)\end{array}$ \\
\hline
\end{tabular}

Table 2: Practical/clinical experience of participants

\begin{tabular}{|c|c|c|c|}
\hline $\begin{array}{c}\text { Method of data } \\
\text { collection }\end{array}$ & $\begin{array}{c}\text { Nursing officers } \\
\text { (NOs) }\end{array}$ & $\begin{array}{c}\text { Community/Public } \\
\text { Health officers } \\
\text { (C/PHOs) }\end{array}$ & $\begin{array}{c}\text { Medical officers } \\
\text { (MOs) }\end{array}$ \\
\hline Focus Group & 6 & 12 & 2 \\
\hline No of participants=20 & $10-22(85.5)$ & $13+(168.3)$ & 2.5 \\
\hline Years of experiences & 14.25 & 14.025 & 1.3 \\
\hline Means & & & \\
\hline
\end{tabular}

Table 3: Health workers perceived competence in PTSD Recognition $\mathbf{N}=\mathbf{2 0}$ Key= no competence (X), Partial competence (PC), Full competence (FC)

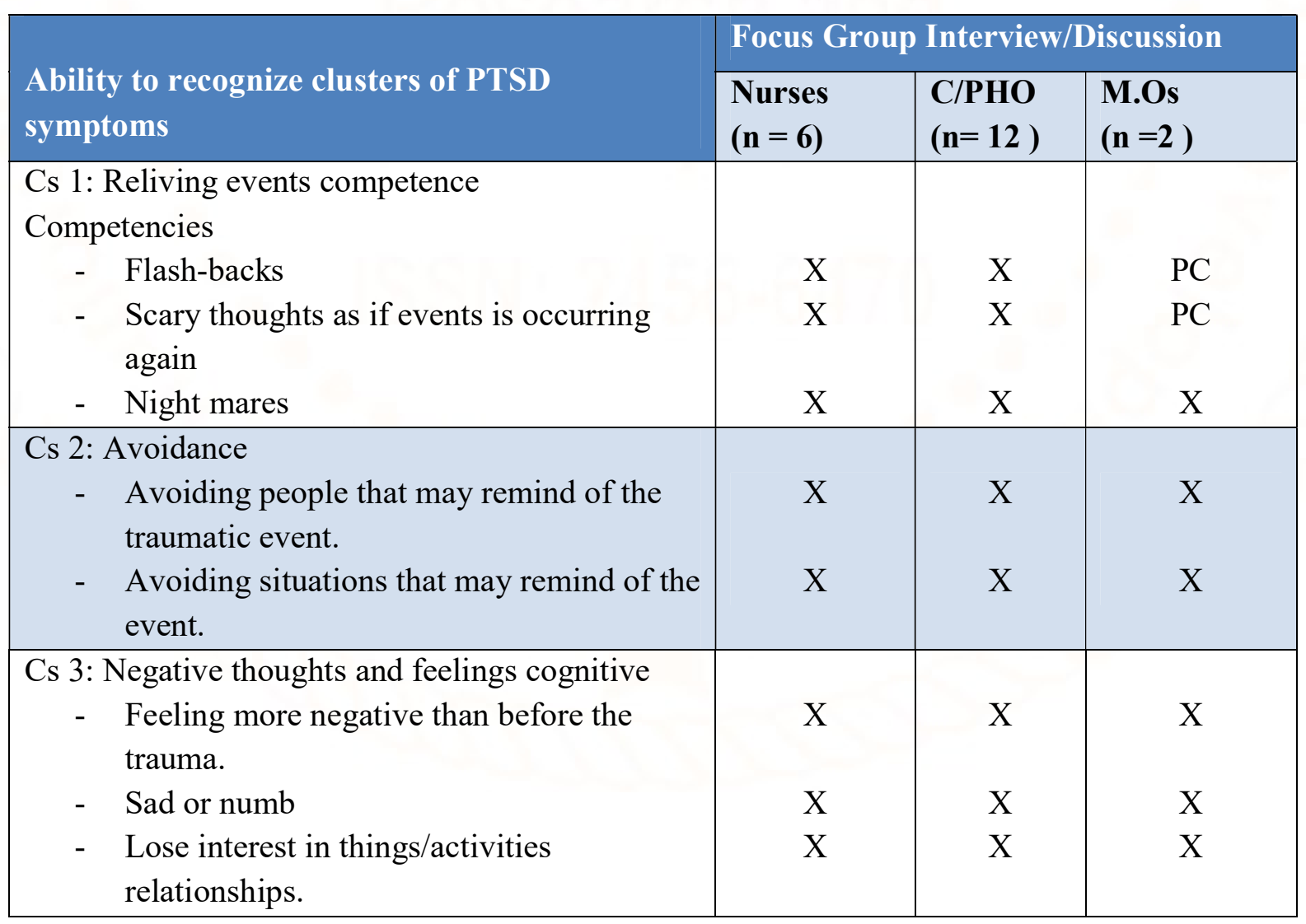




\begin{tabular}{|l|c|c|c|}
\hline - $\quad$ The word is dangerous & $\mathrm{X}$ & $\mathrm{X}$ & $\mathrm{X}$ \\
- Can't trust anyone & $\mathrm{X}$ & $\mathrm{X}$ & $\mathrm{X}$ \\
- Future is bleak/has nothing to offer & $\mathrm{X}$ & $\mathrm{X}$ & $\mathrm{X}$ \\
\hline Cs 4: Hyperarousal & & & \\
- Feeling on edge, jittering & $\mathrm{X}$ & $\mathrm{X}$ & $\mathrm{X}$ \\
- Its hard to relax & $\mathrm{X}$ & $\mathrm{X}$ & $\mathrm{X}$ \\
- Having troubles sleeping or concentrating & $\mathrm{X}$ & $\mathrm{X}$ & $\mathrm{X}$ \\
- Startles easily at surprises. & $\mathrm{X}$ & $\mathrm{X}$ & $\mathrm{X}$ \\
\hline Knowledge of usage of DSM - 5 criteria & & & \\
Competencies & $\mathrm{X}$ & $\mathrm{X}$ & $\mathrm{PC}$ \\
- Duration of symptoms of PTSD & $\mathrm{X}$ & $\mathrm{X}$ & $\mathrm{PC}$ \\
- Types of PTSD & $\mathrm{X}$ & $\mathrm{X}$ & $\mathrm{X}$ \\
- Symptoms severity interfering with & & & \\
$\quad$ activities/relationships & $\mathrm{X}$ & $\mathrm{X}$ & $\mathrm{PC}$ \\
- Certainty and severity of exposure to & & & \\
\hline
\end{tabular}

Table 4: Health workers ability for PTSD management $\mathbf{n}=\mathbf{2 0}$

\begin{tabular}{|c|c|c|c|}
\hline $\begin{array}{l}\text { Competence in usage of various treatment } \\
\text { modalities in the management of PTSD }\end{array}$ & NOs & C/PHOs & MOs \\
\hline $\begin{array}{ll}\text { Competencies } \\
\text { - } & \text { CBT: Eg. CPT, PE, EMDR, MBCT } \\
\text { - } & \text { Psychological skills/modalities of care } \\
\text { - } & \text { Breathing/relaxation exercise } \\
\text { - } & \text { Individual psychotherapy } \\
\text { - } & \text { Group psychotherapy } \\
\text { - } & \text { WHO/ICN - Psychological care for PTSD. } \\
& \text { Skills in psychological intervention } \\
\text { - } & \text { Ethics and legal conditions - cultural } \\
& \text { sensitivity. } \\
\text { - } & \text { Staff/manpower development - policy } \\
& \text { reviews. } \\
\text { - } & \text { Skills in Basic Life support - CPR } \\
\text { - } & \text { Teamwork/collaboration in community } \\
& \text { resources mobilization for resilience. } \\
\text { - } & \text { Long term treatment/making referrals. } \\
\text { - } & \text { Chemotherapy }\end{array}$ & $\begin{array}{c}X \\
X \\
X \\
P C \\
P C \\
X \\
X \\
\text { PC } \\
\text { PC } \\
\text { PC } \\
\text { PC } \\
\text { PC }\end{array}$ & $\begin{array}{c}X \\
X \\
X \\
\text { PC } \\
\text { PC } \\
X \\
X \\
X \\
X \\
\text { PC } \\
\text { PC } \\
X \\
\text { PC }\end{array}$ & $\begin{array}{c}X \\
X \\
X \\
\text { PC } \\
\text { PC } \\
X \\
X \\
\text { PC } \\
\text { PC } \\
\text { PC } \\
\text { PC } \\
\text { PC }\end{array}$ \\
\hline
\end{tabular}




\section{FINDINGS AND DISCUSSIONS}

Health workers across the three focus group interviewed i.e. NOS, $\mathrm{CPHO}$ and MOs reached a consensus that they lacked full competence in the diagnosis and management of PTSD. They however, indicated Partial Competence (Pc) in basic life support skills CPR and in making referrals for PTSD case management in Tertiary Health Institutions. These findings are in agreement with Cnnan s views, that not all clinicians have extensive trauma-focused training, (Cannan, 2016). Kerwick, Jones, Manna and Goldberg (1997) reported the inter-city survey in which the general practitioners highlighted broad range of mental health topics in which they felt they would like to receive further training. Dwyer etal, identified young medical officers needs for more competency in mental health problems identification. (Dwyer, Detweiler, Koseh, 1988).

Nursing and Medical officers agreed that they had only partial competence in group and individual psychotherapy/counselling. They emphasized the importance of psychological care to the IDPs with PTSD.

Health workers also reported awareness that chemotherapy should be used in the management of PTSD but were incompetent in its skilful usage. Ormel and Tiemens (1995) found that primary physicians lack adequate interviewing skills and time to diagnose and manage mental health problems like depression and PTSD. (Tiemens, Philbrick, Connelly, \& Wofford, 1996.). On the average, Iceland primary physicians were competent in detecting behavioural disorders rather than treating them (Haukur, 2007).

Health workers generally reported lack of competence in several management modalities like psychological care especially CBT and skills which included CPT, PE, EMTR, MBCT, Play Therapy and breathing and relaxation exercises $\mathrm{C} / \mathrm{PHO}$ like $\mathrm{CHEW}$, CHA express lack of competence in recognition and management of PTSD. Kilpatrick ( 2015), in this regard opined that the prevalence of traumatic stress has grown rapidly in recent years, requiring health professionals to review standard practices for treating this sequelae, as well as augment their training to provide trauma-specific treatment (Kannan, 2015). Gallagher, (2014) also submitted that psychologists and Psychiatrists need adequate knowledge to care effectively since several patient-related stressors have accounted for the rise in acuity in traumatic stress over time, including vulnerability to risk factors, willingness to seek professional help, and improved access to psychiatric care which allows more individuals with serious mental health concerns to function within highly demanding academic and work environments.

Health workers in this study generally expressed concern and interest in more training on emergency situations and associated health challenges like PTSD so that they may be able to recognize and address current mental health problems effectively, since crises and traumatic incidents are on the increase in our environment and society generally.

It is recommended, therefore, that health workers in Nigeria be given opportunities for training and retraining to augment their skills to respond effectively to emergencies, traumatic incidents and their associated health challenges such as psychotraumas, for diversity within trauma-informed training includes, but is not limited to conceptual issues, empirical models, applied interventions, and policyoriented issues related to trauma (Layne et al., 2014; Mattar, 2011).

Cook et al. (2011) reported a study which assessed practicing psychologists' interest in additional clinical training on trauma-related issues and topics. Over $60 \%$ of survey respondents expressed interest in participating in additional training to learn more about trauma-related clinical topics, speaking to the gap between education around trauma and need for learning.

Health personnel working with the internally displaced persons in the Plateau state of Nigeria indicated interest in more training, and expressed the importance of being competent in both recognition of PTSD among the IDPs and utilization of appropriate methods / skills in their care. This is in line with NICE's (2005) recommendation that, treatment should be delivered by competent individuals who have received appropriate training. This implies the need for re-training of the health professionals involved in the provision of health services in the emergency situations as well as to the victims of trauma. 
Furthermore, Cook \& Newman, (2014) suggested that additional for a be provided to promote knowledge sharing such as creating or joining a journal club, seeking opportunities for professional mentorship, attending local psychology practice associations, or sharing web-based trainings and seminars with colleagues to demonstrate commitment to make critical review of published literature and integrate general competencies and clinical skills with traumaspecific knowledge (Cook \& Newman, 2014).

\section{REFERERENCES}

1) American Psychiatric Association APA (2013) Diagnostic And Statistical Manual of Mental Disorders (DSM-5) $5^{\text {th }}$ ed. Washington DC.

2) Cloitre, M., Courtois, C.A., Charuvastra, A., Carapezza, R., Stolbach, B.C. and Green, B.L. (2011) 'Treatment of complex PTSD: Results of the ISTSS expert clinician survey on best practices', Journal of traumatic stress, 24(6), pp.615-627. [Online]. Available at: http://onlinelibrary.wiley.com/doi/10.1002/jts.206 97/full (Accessed: 14 ${ }^{\text {th }}$ September, 2016).

3) Cook, J.M. and Newman, E., 2014. A consensus statement on trauma mental health: The New Haven Competency Conference process and major findings. Psychological Trauma: Theory, Research, Practice, and Policy, 6(4), p.300. [Online]. Available at: http://psycnet.apa.org/journals/tra/6/4/300/ (Accessed: 15 ${ }^{\text {th }}$ November, 2016).

4) Cook, J.M., Dinnen, S., Rehman, O., Bufka, L. and Courtois, C. (2011) 'Responses of a sample of practicing psychologists to questions about clinical work with trauma and interest in specialized training', Psychological Trauma: Theory, Research, Practice, and Policy, 3(3), p.253. [Online]. Available at: http://psycnet.apa.org/journals/tra/3/3/253/ (Accessed: 23 ${ }^{\text {rd }}$ November, 2016).

5) Courtois, C.A. and Gold, S.N. (2009) 'The need for inclusion of psychological trauma in the professional curriculum: A call to action', Psychological Trauma: Theory, Research, Practice, and Policy, 1(1), p.3. [Online]. Available at: http://psycnet.apa.org/journals/tra/1/1/3/

(Accessed: $1^{\text {st }}$ October, 2016)

6) Figley, C.R. (2013) Trauma and its wake, Vol 1, Routledge. Available online at: https://books.google.co.uk/books?hl=en\&lr=\&id= OF7azkxcj2gC\&oi $=$ fnd\&pg $=$ PP $1 \& d q=$ Trauma $+\mathrm{a}$ nd + its + wake\&ots $=y I 05 \_O a C V 2 \&$ sig $=$ WGDj 1vrp MPHCC9ki32FpxaqXd6 $\mathrm{I} \# \mathrm{v}=$ onepage \& $\mathrm{q}=$ Trauma $\% 20$ and $\% 20$ its $\% 20$ wake $\& \mathrm{f}=$ false $\left(\right.$ Accessed: $21^{\text {st }}$ October 2016).

7) Gallagher, R.P. (2014) National survey of college counselling centres. International Association of Counselling Services, Inc. International Association of Counselling Services, Inc. [online]. Available at: http://www.iacsinc.org (Accessed: $30^{\text {th }}$ November, 2016).

8) Hansen, M., Andersen, T.E., Armour, C., Elklit, A., Palic, S. and Mackrill, T. (2010) 'PTSD-8: a short PTSD inventory', Clinical Practice \& Epidemiology in Mental Health, 6(1). [Online]. Available at: http://benthamopen.com/FULLTEXT/CPEMH-6101 (Accessed: 10 ${ }^{\text {th }}$ November, 2016).

9) Kannan, D. (2016) 'Clinical-competence-intreating-traumatic-stress-considerations-for-earlycareer-psychologists', Trauma Psychology News, American Psychological Association, Vol 11, no 2. [Online]. Available at: http://traumapsychnews.com/2016/03/clinicalcompetence-in-treating-traumatic-stressconsiderations-for-early-career-psychologists/ (Accessed: 20 ${ }^{\text {th }}$ November, 2016).

10) Kilpatrick, D.G., Resnick, H.S., Milanak, M.E., Miller, M.W., Keyes, K.M. and Friedman, M.J. (2013) 'National estimates of exposure to traumatic events and PTSD prevalence using DSM-IV and DSM-5 criteria', Journal of traumatic stress, 26(5), pp.537-547. [Online\}. Available at: http://onlinelibrary.wiley.com/doi/10.1002/jts.218 48/full (Accessed: $12^{\text {th }}$ November, 2016).

11) Loke, A.Y. and Fung, O.W.M. (2014) 'Nurses' competencies in disaster nursing: Implications for curriculum development and public health', 
International journal of environmental research and public health, 11(3), pp.3289-3303. [Online]. Available at: http://www.mdpi.com/16604601/11/3/3289/htm (Accessed: $14^{\text {th }}$ November, 2016).

12) Mattar, S. (2011) 'Educating and training the next generations of traumatologists: Development of cultural competencies', Psychological Trauma: Theory, Research, Practice, and Policy, 3(3), p.258. [Online]. Available at: http://psycnet.apa.org/journals/tra/3/3/258/

(Accessed: $16^{\text {th }}$ November, 2016).

13) National center for PTSD (2014) Retrieved from http://.ptsd.va.gov access (2016).

14) NICE ( 2005 ) Management of PTSD in adults and children in primary and secondary care guidelines [CG26] Published date: March 2005 www.nice.org.uk

15) Usher, K. (2010) 'Editorial: Are we ready? Preparing nurses to respond to disasters and emerging infectious diseases', Journal of clinical nursing, 19(11-12), and pp.1483-1484. [Online]. Available at: http://onlinelibrary.wiley.com/doi/10.1111/j.13652702.2009.02979.x/full (Accessed: $25^{\text {th }}$ November, 2015).

16) Weiner, E., Irwin, M., Trangenstein, P. and Gordon, J. (2005) 'Emergency preparedness curriculum in nursing schools in the United States', Nursing Education Perspectives, 26(6), pp.334-339. [Online]. Available at: http://journals.lww.com/neponline/Abstract/2005/ 11000/EMERGENCY_PREPAREDNESS_CURRI CULUM_in_Nursing. $\overline{5}$.aspx (Accesse $\bar{d}: \quad 22^{\text {nd }}$ November, $\overline{2016) .}$

17) WHO; International Council of Nurses (2009). ICN Framework of Disaster Nursing Competencies, WHO, Geneva, Switzerland. 